\title{
Curriculum Innovation and Information and Communication Technology (ICT): An Analysis
}

\author{
Dr. Ebisine, Sele Sylvester \\ Department of Mathematics, College of Education, Warri, Delta State, Nigeria \\ Email: ebisineselesylvester@yahoo.com
}

Doi:10.5901/mjss.2015.v6n4s1p264

\begin{abstract}
Today, the world is changing dramatically in terms of the ways we learn and socialize due to new technologies and techniques engendered by the widespread use of information and communication technology. Thus, this paper examines the concepts of curriculum and curriculum innovation and Information and Communication Technology (ICT); instructional design models for ICT integration and role of ICT in enhancing teaching - learning. Other areas addressed by the paper include the impact of ICT on curriculum innovation in Nigeria education system and teacher competencies for ICT integration in the school curriculum.
\end{abstract}

Keywords: Curriculum Innovation, Information and Communication Technology, ICT Integration, Teacher Competencies, Instructional Design Models

\section{Introduction}

Education is an important tool for development, as well as the vital element in the process of social change, technological and economic growth. Such development, growth and change usually occur with the curriculum, which serves as the instrument through which the desired changes in the society envisaged by the educational policy are given concrete manifestation (Inyong, 2009). To ensure excellent curriculum plan at the implementation state, the use of Information and Communication Technology (ICT) was introduced as an innovation in teaching and learning. The innovation has been emphasized in Section 11 (102) (A) of the National Policy on Education (FRN, 2004) that a Network of Educational Services Centres in Nigeria (NESCN) shall be set up to provide a forum for exchange of ideas on the development and use of innovative materials for improvement of education. All states, Teachers Resource Centre, University, Institute of Education and other professional bodies shall belong to the network of Information and Communication Technology. The fact that the educational system has undergone major structural changes. That is from pedagogical methodology to the current phase of more sophisticated, but user friendly technology-based instructional methodology, there is need to introduce ICT into the Nigerian schools' curriculum as an innovation.

Furthermore, the prominent role of ICT in the advancement of knowledge and skills necessary for effective functioning in the modern world has been stressed, but it should be noted that the effective introduction of ICT into our curriculum, educational system, and subsequently into the classrooms and other societal settings, is a complex, multifaceted process that involves not just the technology, but indeed, enough initial financial capital for acquiring the technology; but also the right curriculum and pedagogical manpower, institutional readiness, teachers' competences, and long-term financing among others (Umoreh, 2006). The paper therefore examines the concept of curriculum, ICT, some instructional design models for ICT integration, as well as the impact of ICT on curriculum innovation.

\section{Concept of Curriculum}

There are several definitions of the word 'Curriculum' by different scholars in the field. One of the most universally accepted of these is that provided by Tanner and Tanner (1975) who defined the term as planned and guided learning experiences and intended learning outcomes, formulated through the systematic reconstruction of knowledge and experiences, under the auspices of the school, for the learner's continuous and willful growth in social competence. This definition shows that when curriculum is well planned it will lead to all round development of the learner. Okonkwo and Ozurumba (1989) stressed that curriculum is a planned and directed activity programme meant to facilitate the achievement of educational purposes. Educational purpose can only be achieved if the curriculum content and learning experiences are well implemented. As noted by Ogboji (2008) Nigeria system of education has to be geared towards self- 
realization, better human relationship, individuals and national economic, political, scientific and technological progress. A worthwhile curriculum is never static. It is dynamic. When analyzed, the intended objectives, the learning experiences, the methods of instruction, the method of evaluation, all parts of or steps in curriculum development have continued to change. There are many factors that necessitate curriculum renewal (Anekwe and Obi, 2009). Okeke as cited in Anekwe and Obi (2009) has highlighted factors that influence curriculum revision. Some of them included:

- $\quad$ Change in the objectives of education emanating from change in societal values, belief, traditions, etc.;

- $\quad$ Change in what is known about learning process;

- $\quad$ Change in the system of education; and

- Change necessitated by feedback from curriculum evaluation.

Curriculum is operated within a system, so, it is understandable that changes in education system will call for a revision of curriculum. For instance, one expect a curriculum innovation due to information technology revolution that is dramatically changing every facet of human life from educational, industry, economy, polities, culture and medicines to a myriad of others.

\section{Meaning of ICT}

ICT is an acronym for information and communication technology. It is a technology that acquires, processes, stores, retrieves at will, disseminates, vocal, pictorial, textual and numerical information by combining data processing and telecommunication techniques. ICT also stands for the various ways the computer work together with other telecommunication equipments which are needed in data processing and information transmission to solve different aspects of human endeavour (Eze, 2007). In one sense, Eguridu (2008) presented ICT as a technology that merges computer with high speed communication links carrying data, sound and videos. ICT, he emphasized, is an umbrella term that refers to all technology for communication of information. According to him, it includes any medium to record information e.g. paper, magnetic disk flash.

ICT is a process of networking - connecting any part of the world by mere touching a combination of keyboard buttons on electronic device like radio, television, telephone, computer and so on with this innovation in our ever changing society, it is crystal clear that more pressures will be on the young people mostly students. Thus, the need to fully inculcate ICT into the Nigerian education system in order to gradually bring them to the reality of the universal phenomenon (Orukokan, Olaleye, Odumosu and Akinniyi, 2009).

The important role of ICT in the advancement of knowledge is well recognized by Federal Government of Nigeria as contained in the National Policy on Education that there is an urgent need to integrate ICT into education in Nigeria and that Government shall provide facilities and necessary infrastructures for promotion of ICT at all levels of education (FRN, 2004).

\section{Instructional Design Models for ICT Integration}

Specialists in instructional design have developed many instrumental design models to assist teacher - designers plan their ICT integration into the curriculum. Among those developed are (1) Kolb's influential model of the learning process which usefully lends itself to the practical requirements of ICT integration in terms of how it outlines a practice - reflection cycle proceeding as distinct stages of concrete experience, observation, conceptual abstraction and testing, (2) Sandholtz, Ringstaff and Dwyer's (2000) model of instructional 'evolution' consisting of five stages (entry, adoption, adaptation, appropriation and invention), (3) the ASSURE (Analyze learners; State the objective; Select method, media and materials; Require learning participation; Evaluation and revise) model, (4) the WisebQuests model which is an inquiry-oriented activity in which some or all of the information that learners interact with comes from sources on the Internet, (5) the ICARE (Introduction; Connect; Activity; Reflect; Extend) model (Hoffman and Ritchie, 1998) and (6) model-a systematic model for designing ICT integration plan consisting of seven stages (Problem Statement; Learning Objectives; Technology Required; Rational; Strategies; Assessment; Reflection). These models show guideline for incorporating various resources and tools into teaching and learning (Ejiwale, 2009: 100 - 101).

\section{Impact of ICT on Curriculum Innovation in Nigeria}

\subsection{Programmed Instruction}

This is a designed instruction arranged in sequence, to help the learners attain specific objectives as mapped out by the 
teacher or instructor. With the use of ICT teachers can effectively teach the learner at his/her own rate, and at his or her own time and convenience. Moreover, the rate of accuracy with which the learner learns will determine whether he or she should proceed to the next step/stage, or to review a bit, or go back to study the earlier instruction from the beginning.

\subsection{Administrative Work}

In general, teachers are also administrators in their right, at all levels of our education system. As administrators, they need to collect and disseminate information. The best and efficient way of achieving that is through ICT. Administratively, educational administrators and teachers could use ICT to function through the following media:

- Intercom - Can allow teachers in different rooms/parts of a building or premises to administer by sending information, directives, decisions, etc. across to each other.

- Telephony - Can be used in sending text messages and phoning people in any part of the world, thereby reducing travel risks/costs, time and administrative bottle-necks.

- Teleconferencing - Whereby meetings could be held among teachers and the authorities in different locations using televisions.

- The Internet/E-Mail - Possible through computer network that can allow teachers in different parts/locations of the world to exchange information, mails, pass on directives, etc. for administrative purposes, online registration and fee payments.

- Computer/Printer - Teachers could use these devices to store programmes and information; in writing and printing documents, calculating and communicating on the internet.

- Fax Machine - Could be used by administrators in the school system to send message across for administrative purposes. Also, applicants/students can use this device to fax their application forms to the school authority.

\subsection{Distant Learning}

Apart from the regular school programmes, workers can read and study while they are also working. With the internet, the distant learning programme is very easy and convenient. Curriculum/education reforms should be tailored towards the modern day realities in technology.

\subsection{Computer Literacy/Research Work}

This, indeed, is an information age. A successful integration of computers, telecommunications and knowledge in industries had led to a global electronic resource sharing mechanism, referred to as computer networks. Nigeria should take a cue from the advanced countries whose libraries are automated or computerized, and work towards achieving same. Nigeria should also plan on providing automated libraries to be strategically located in the six geo-political zones of the country.

\subsection{Recording of Tests/Assessments and Examination Results}

As schools and institutions are now saturated with large number of students, the computation of tests and examination results manually becomes very complex and cumbersome. Test scores, assessment and examination results are very sensitive issues that require efficient, accurate and secured handling (Inyong, 2009: 47 - 49).

Fajuyigbe, O. \& Ekuobase, G. (2000) outlined the benefits of ICT as regards the recording of scores and tests thus:

a. Processing Speed: Computers, being super-fast, can perform tasks a lot more quickly than human beings. It greatly reduces delays in result processing.

b. Reliability and Consistency: Computer is a machine and does not wear out easily. Computers are less error prone than human beings.

c. Large and Durable Storage Capacity: The idea of the moth or insects eating records is eradicated. Computer can also store large units of information.

d. Security: Answer sheets are not likely to be missing in transit. More so, the computer cannot be bribed or easily lobbied like men.

e. Information Access/Retrieval: It will only take the computer seconds to supply certain information that may 
take a clerk some days.

f. Convenience: Automated system has always been a relief to man's tedious ways of doing things. For instance, the dictionary is provided for spelling checks.

\section{Teacher Competencies for ICT Integration School Curriculum}

Teachers are aware that the wise use of technology can enrich learning environments and enable students to achieve marketable skills. To use ICTs effectively to improve the way school subjects should be taught and enhance student understanding of basic concepts, competencies in ICT integration is essential. The following are list of competencies for ICT integration in the school curriculum:

1. understanding the existence of various technology resources in education and their functional differences in supporting teaching and learning;

2. demonstrating knowledge and skills for operating technology tools applicable for education (productivity tools, problem-solving tools, communication tools, research tools);

3. understanding the diversity of learning styles with students and the possibilities of using ICT to fit personal learning needs;

4. designing effective learning experiences and creating rich learning environments with the support of ICT;

5. understanding that ICT enables multiple representations of knowledge and makes available extensive resources;

6. designing technology-enhanced representation and presentation of curriculum knowledge and recognizing learning resources;

7. demonstrating knowledge and skills for acquiring and processing learning resources with ICT tools and using the resources for educational purposes in fair ways (Ejiwale, 2009: 100).

\section{Conclusion}

In this paper, we saw that ICT is an innovation in teaching and learning in Nigeria educational system. We also saw that no curriculum is ever static but rather dynamic hence there is need for curriculum renewal. Since this is so, the impact of ICT in curriculum and teacher competences for ICT integration in the school curriculum were highlighted.

\section{References}

Anekwe, J.U. \& Obi, R.O. (2009). Restructuring secondary school curriculum through the integration of ICT best practices: Implications for total persons. Journal of Curriculum Studies, 16 (12).

Eguridu, C. (2008). Information communication technology and efficiency in public examination. The case of the West African Examination Council. Journal of Educational Assessment in Africa.

Ejiwale, O.A. (2009). Integrating information and communication technology in the Chemistry curriculum. Journal of Curriculum Studies, 16 (2); $96-110$.

Eze, R.O. (2007). Improving the Quality of Teaching and Learning in Upper Basic Education in Nigeria through Information and Communication Technology (ICT). A Paper Presented at the 20 Annual Conference of the Curriculum Organization of Nigeria (CON) held at the Faculty of Education Auditorium, Abia State University, Uturu on Wednesday 19th - Saturday 22 ${ }^{\text {nd }}$ September, 2007.

Fajuyigbe, O. \& Ekuobase, G. (2000). The Scoring and Computerized Examination Recording. A Workshop Paper Presented at Federal College of Education (Techincal), Asaba.

Federal Republic of Nigeria (2004). National Policy on Education. Lagos: NERDC.

Inyong, A.U. (2009). Curriculum innovation and information and communication technology (ICT): Implications for counselling. Journal of Curriculum Studies, 16 (2).

Ogboji, B.A. (2008). Curriculum reform in cultural and creative art for the attainment of millennium development goals (MDGs). Journal of Educational Reforms and the Attainment of the Millennium Development Goals (MDGs): The Nigerian Experience, 13 (17).

Okonkwo, C.E. \& Ozurumba, M.M. (1987). Fundamental Concept in Education. Owerri: Total Publishers Ltd.

Orukokan, A.F., Olaleye, B.O., Odumesu, M.O. \& Akinniyi, F.E. (2009). Evaluating the compliance of present secondary school curriculum with information communication technology (ICT). Journal of Curriculum Studies, 16 (1).

Tanner, D. \& Tanner, L. (1975). Curriculum Development Theory. New York: Macmillan.

Umoren, E. (2006). Information and communication technology and curriculum. Nigerian Journal of Curriculum Studies, 2 (1). 